\title{
Prevalence and Risk Factors of Hearing Loss Using the Korean Working Conditions Survey
}

\author{
Kyoo Sang Kim and Oh Jun Kwon \\ Occupational Safety and Health Research Institute, Korea Occupational Safety and Health Agency, Incheon, Korea
}

Received July 23, 2012

Revised August 26, 2012

Accepted September 6, 2012

\section{Address for correspondence}

Kyoo Sang Kim, MD, PhD

Occupational Safety and Health

Research Institute, Korea

Occupational Safety and Health

Agency, 478 Munemi-ro,

Bupyeong-gu, Incheon 430-711,

Korea

Tel $+82-32-510-0823$

Fax +82-32-518-0862

E-mail kobawoo@kosha.net
Background and Objectives: The hearing loss of workers can occur when they are affected by age, otologic disease, and work-related risks such as noise and chemicals. Based on the Korean Working Conditions Survey (KWCS) in 2010, this research aimed to estimate the prevalence rate of hearing loss and to identify the risk factors affecting its occurrence. Subjects and Methods: The subjects were 10019 employees who completed an interview conducted as part of KWCS in 2010. The prevalence rate of hearing loss according to sex, age, education, income, smoking, drinking, hypertension, industrial type, occupations, employment status, working period, and hazards at the workplace were assessed. The factors that could affect the occurrence of hearing loss were investigated based on a logistic regression analysis. Results: The prevalence rate of hearing loss was $2.7 \%$. In a logistic multivariate analysis, sex, age, occupations, working period, noise, and exposure to chemicals showed statistically significant correlations to the occurrence of hearing loss. The adjusted odd ratios were as follows: 1.74 [95\% confidence interval (Cl), 1.03-2.96] for males, 2.11 (95\% Cl, 1.14-3.89) for those in their 40s, 2.24 (95\% Cl, 1.19-4.20) for those in their 50s, 2.21 (95\% Cl, 1.18-4.15) for manage/ professional works, $2.73(95 \% \mathrm{Cl}, 1.69-4.41)$ for manufacturing, 2.07 (95\% Cl, 1.36-3.15) for those who have worked for more than 20 years, 1.72 (95\% Cl, 1.14-2.58) for noise exposure, 1.53 (95\% Cl, 1.02-2.30) for vibration exposure and 1.58 (95\% Cl, 1.11-2.24) for chemical exposure. Conclusions: The overall occupational and non-occupational risk factors related to employees' hearing loss were reviewed. In addition to the exposure to noise, occupational risks of hearing loss, such as isolated exposure to vibration and chemicals, and combined exposure to noise and these hazards, were identified. Multiple exposure to hazards, along with prolonged noise exposure increased the risk of hearing loss. Korean J Audiol 2012;16:54-64

KEY WORDS: Hearing loss · Risk factors · Noise $\cdot$ Chemicals.

\section{Introduction}

In general, hearing loss can be generated by several reasons, such as age, noise, otologic disease, head injury, genetic factors, and drugs. Age-related hearing loss (presbycusis) has been considered to have a correlation to old age only, but recent studies reported that it was defined as overall hearing loss that resulted from many types of physiologic degenerations, such as hearing loss through the exposure to noise, ototoxic drugs, and medical conditions. The environmental risk factors affecting hearing loss are noise, vibration, head injury, organic solvents, heavy metals, ototoxic drugs, smoking, and alcohol. ${ }^{1)}$

Industrial workers can be easily exposed to industrial noise, unlike the general population group, because noise occurs in- evitably in their workplaces. Thus, this workplace noise acts as a source to noise-induced hearing loss (NIHL). Specifically, occupational factors, like noise exposure level, frequency, exposure time and period, and individual susceptibility are the main reasons that generate hearing loss. Individual susceptibility can be affected by many factors like sex, race, age, initial hearing, cardiovascular risks such as smoking, overweight, hypertension, and diabetes mellitus, and interaction of noise and other noxious agents.

There are several forms of health observations associated with the hearing of the population groups in Korea, such as the General Health examination, Special Health Examination, Korean National Health and Nutrition Examination Survey (KNHANES), and Korean Working Conditions Survey (KW- 
CS). However, General Health Examination has problems with reliability of the test result and there is the possibility of a false negative, while simple check of normality of hearing ability is possible by this examination. In case of Special Health Examination, levels of hearing loss and relationships between noise and NIHL can be identified, but there is limitation in utilizing the data due to the lack of information on other risk factors affecting the deterioration of hearing ability. On the other hand, the KNHANES is lacking in the evaluation of the exposure to hazardous factors, as well as having the job classifications of subjects not being specified, since the aim of this survey is not for the workers' labor environment and the work-related diseases. ${ }^{2)}$

Eurostat investigated the risk factors for both general and occupational diseases, and reported the incidence rate of each disease, using the reported data in the European schedule for occupational disease. ${ }^{3)}$ Meanwhile, the European Foundation for the improvement of Living and Working Conditions has conducted European Working Conditions Survey (EWCS) since 1991, which is designed to improve the working conditions and to establish a new policy that will enhance the quality of life through the assessment on the work environment including the hazardous factors to the workers. A recent 5th edition of EWCS was conducted with 42765 workers in a number of European countries (1000-4000 workers per country after considering the population and economic size of each country). ${ }^{4)}$

The first KWCS was conducted in 2005, and the second KWCS was carried out in 2010. The comparison of physical factors, work-related symptoms, and the number of work-related leaves of KWCS 2005 with those of EWCS has been reported. ${ }^{5)}$ This study used the data of the second KWCS, a household survey subjected to workers based on the probability proportional to systematic sampling of nationwide stratification. In this survey, socio-demographic factors such as sex, age, region, education level, and monthly income, medical risk factors such as hypertension and obesity, health behavior factors such as smoking and drinking, occupational factors like industry type, occupations, employment status, number of employees, and working period, and the exposure to hazardous factors such as noise, vibration, and chemicals were included. ${ }^{6}$ Thus, this research aimed to estimate the prevalence rate and to identify risk factors that affected the occurrence of hearing loss under the definition that hearing loss occurs when workers have had a hearing problem for the past 12 months.

\section{Subjects and Methods}

\section{Subjects}

The second KWCS, composed as an interview type, used the household survey method and it was conducted from the 20th of June, 2010 to the 10th of October, 2010. The survey subjects were employees who were over 15 years old and who have worked for more than one hour for the past week starting from the time of the survey. The subjects were chosen using a probability proportional to the systematic sampling of stratification in 265350 enumeration districts and 15887128 families, with the exception of people on islands, technical facilities, special welfare institutions and foreign enumeration districts.

For this study, 10019 workers who were over the age of 15 years old and self-employed without employees, self-employed with employees, employees, and unpaid family workers were selected as the research subjects. 'Self-employed without employees' are workers who perform professional work or manage their business through individual responsibility, themselves, or with unpaid family workers. 'Self-employed with employees' are workers conducting their business with more than one employee. 'Employees' are workers who get paid for their labor as a wage, salary, or daily wage. Lastly, 'Unpaid family workers' could be defined as employees who work in a family or relative owned shop or business for more than 18 hours in the past week without a salary.

\section{Methods}

In this study, 267 (2.7\%) people responded 'YES' to the question, 'have you ever had any hearing problems for the past 12 months?' in the second KWCS, with these people being defined as having hearing loss.

Industrial classification was categorized depending on the Korean Standard Industrial Classification through the following: mining, agriculture, manufacturing, construction, transportation, and others (electricity, gas, and water supply, wholesale and retail trade, accommodation and food service activities, information and communications, financial and insurance activities, real estate activities and renting and leasing, business services, public administration, defense and compulsory social security, education, human health and social work activities, arts, sports and recreation related services, repair and other personal services). Occupations were classified by manage/professional work (professionals, senior managers), manual work (craft and related trade workers, machine operators and assemblers, and elementary occupations), and office service work (clerks, sale workers, service workers). Hazardous factors that can affect workers' hearing ability are noise, vibration and chemicals at the workplace; relevant hazardous factors were classified into non-exposure (exposed for $1 / 4$ or less of the working hours), and exposure (exposed for half or more of the working hours). 
Also, several variables were defined in order to examine the prevalence rate of hearing loss as follows: age (20s, 30s, 40s, $50 \mathrm{~s}$ ), region (six major cities including Seoul, others), number of employees (1-4, 5-49, 50-299, over 300), working period (4 years or less, 5-9 years, 10-19 years, over 20 years), health behavior like smoking and alcohol drinking (currently in use), chronic diseases like hypertension and obesity (currently diagnosed), education (graduate of high school, above college), and monthly income (below 2000000 won and above 2000000 won).

\section{Statistical analyses}

In order to identify the factors that affect hearing loss, univariate and multivariate logistic regression analyses were performed through a chi-square test with the checking of several factors, such as individual socio-demographic factors (sex, age, region, education level, and monthly income), work factors (industry type, occupations, employment status, number of employees, working period, and exposure to hazards at the workplace), health behavior (smoking and alcohol drinking), and medical risk factors (hypertension and obesity). Furthermore, to investigate whether hazardous factors were exposed and how exposure levels in the workplace affect hearing loss, noise was separated into categories. In regards to other factors like noise, vibration, and chemicals, this study represented an odds ratio (OR) from the univariate logistic regression analyses of hearing loss, after separating into non-exposure, uniexposure, and the multi-exposures, and the multivariate regression analyses under controlled individual risk factors like sex, age, working period, smoking, alcohol drinking, hypertension, and obesity. This research analyzed the prevalence rate and risk factors of hearing loss using IBM SPSS Statistics 18 program as an interview survey through probability that is proportional to the systematic sampling of nationwide stratification.

\section{Results}

\section{Sex distribution depending on the general characteristics of the survey subjects}

Among 10019 research subjects, the number of males was $5850(58.4 \%)$ and the number of females was $4169(41.65 \%)$. Generally, male subjects were older than female subjects. The results of the education level indicated that the rate of males who graduated to above college and gained over 2000000 won as a monthly income was higher than that of females. The rate of males who worked in manufacturing, construction, and transportation was higher than that of females, while the rate of females engaged in agriculture and other industries was higher than that of males. In regards to occupations, the rate of males engaged in manage/professional and manual work was higher than that of females. More males were engaged in larger companies than females, and their working period was also longer. The male workers' exposure rate to hazardous factors like noise, vibration, and chemicals was higher than that of female workers. Males did more smoking and alcohol drinking (Table 1).

\section{Distribution of hearing loss depending on related factors of the survey subjects}

The prevalence rate of hearing loss was found to be a total of 267 (2.7\%) workers. A significant difference could be identified between 191 (3.3\%) males and 76 (1.8\%) females. Based on the results from the examination of the differences in distribution through the main variables related to hearing loss of each male and female, in the case of males, there were considerable statistical differences in the rate of people having hearing loss in age, education, monthly income, hypertension, industry type, occupations, employment status, working period, noise, vibration and chemicals exposures except for region, number of employees, obesity, smoking and alcohol drinking. In the case of females, the data represented significant differences in age, region, education, monthly income, industry type, occupations, employment status, working period, noise and vibration exposures. The hearing loss tend to occur more frequently in older ages, in small-size cities, in construction, manufacturing, agriculture, and mining industries, in manual work, and in longer working period. In addition, the workers who were exposed to noise, vibration, and chemicals at the workplace, and the workers with hypertension, low education level, and low monthly income showed higher rate of hearing loss (Table 2).

Factors affecting the hearing loss of the survey subjects

In the case of the univariate analysis, the hearing loss risk for males was increased compared with female (OR 1.83, 95\% CI, 1.40-2.39). In regards to age, ORs was $2.72(95 \%$ CI, 1.61-4.59) for subjects in their 40s and 4.02 (95\% CI, 2.42-6.66) for subjects in their 50s, when compared with subjects in their 20s. For the region analysis, OR of workers in other cities was higher than that of the major cities. There were statistically significant ORs; 1.54 (95\% CI, 1.21-1.97) for smokers and 2.05 (95\% CI, 1.32-3.19) for hypertension. ORs were 2.11 (95\% CI, 1.39-3.21) in construction, 1.95 (95\% CI, 1.42-2.68) in manufacturing, 3.55 (95\% CI, 2.50-5.06) in agriculture, and 35.33 (95\% CI, 8.44-147.85) in mining in comparison with reference. Related to the type of occupations, OR for manual work was 4.02 (95\% CI, 2.99-5.41) 
Kim KS, et al.

Table 1. Characteristics of subjects by sociodemographic, medical, and occupational risk factors, Korea Working Conditions Survey 2010

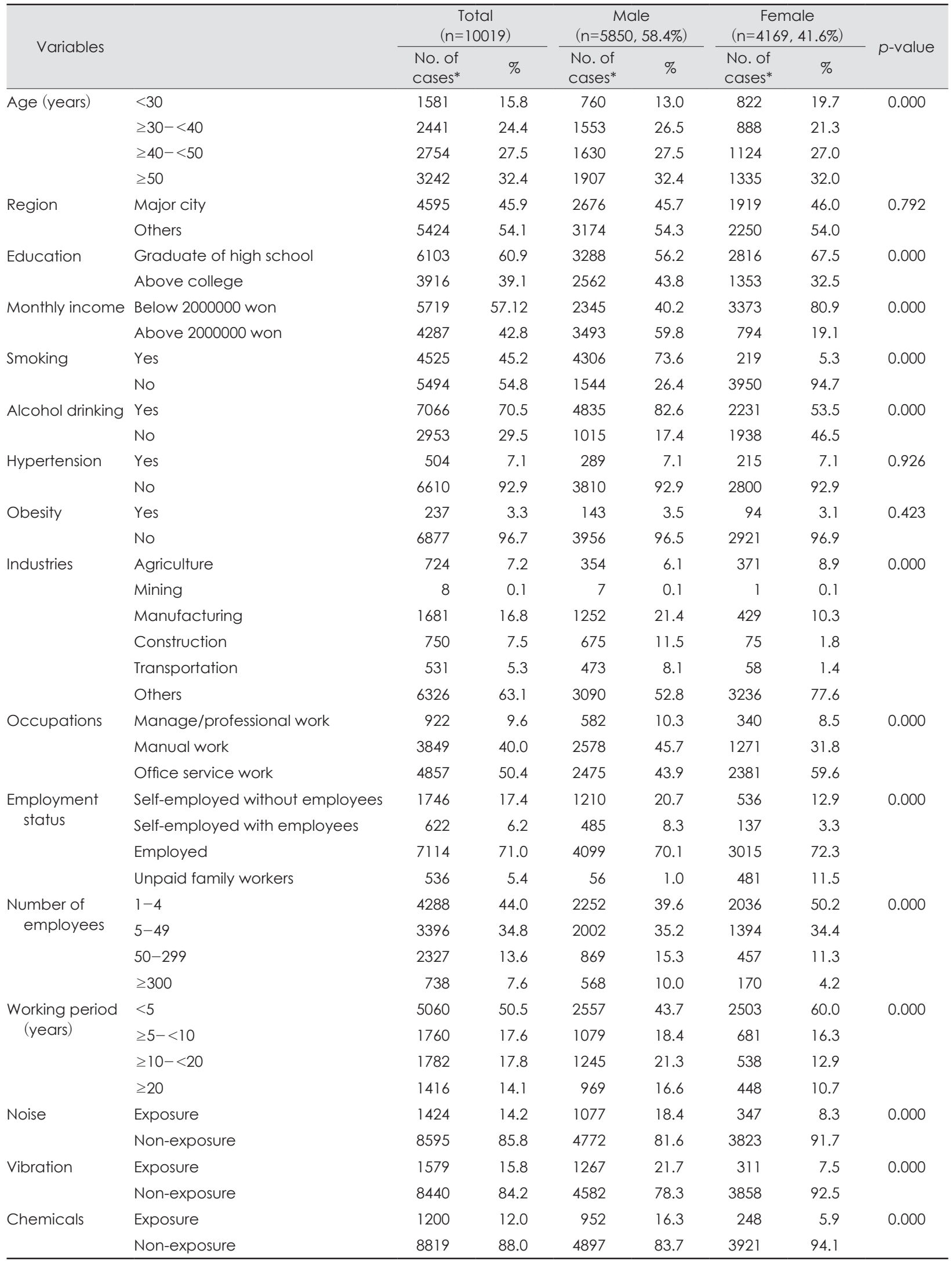

*the number of subjects who experienced hearing loss 
Table 2. Prevalence of hearing loss by sociodemographic, medical, and occupational risk factors, Korea Working Conditions Survey 2010

\begin{tabular}{|c|c|c|c|c|c|c|c|c|c|c|}
\hline \multirow{2}{*}{ Variables } & & \multicolumn{3}{|c|}{ Total $(n=267,2.7 \%)$} & \multicolumn{3}{|c|}{ Male $(n=191,3.3 \%)$} & \multicolumn{3}{|c|}{ Female $(n=76,1.8 \%)$} \\
\hline & & $\begin{array}{l}\text { No. of } \\
\text { case* }\end{array}$ & $\%$ & p-value & $\begin{array}{l}\text { No. of } \\
\text { case* }\end{array}$ & $\%$ & p-value & $\begin{array}{l}\text { No. of } \\
\text { case* }^{*}\end{array}$ & $\%$ & $p$-value \\
\hline \multirow[t]{4}{*}{ Age (years) } & $<30$ & 17 & 1.1 & 0.000 & 8 & 1.1 & 0.000 & 9 & 1.1 & 0.000 \\
\hline & $\geq 30-<40$ & 33 & 1.4 & & 26 & 1.7 & & 7 & 0.8 & \\
\hline & $\geq 40-<50$ & 80 & 2.9 & & 66 & 4.0 & & 14 & 1.2 & \\
\hline & $\geq 50$ & 137 & 4.2 & & 90 & 4.7 & & 47 & 3.5 & \\
\hline \multirow[t]{2}{*}{ Region } & Major city & 103 & 2.2 & 0.015 & 79 & 3.0 & 0.211 & 24 & 1.3 & 0.011 \\
\hline & Others & 165 & 3.0 & & 113 & 3.6 & & 52 & 2.3 & \\
\hline \multirow[t]{2}{*}{ Education } & Graduate of high school & 204 & 3.3 & 0.000 & 144 & 4.4 & 0.000 & 60 & 2.1 & 0.035 \\
\hline & Above college & 63 & 1.6 & & 47 & 1.8 & & 16 & 1.2 & \\
\hline \multirow[t]{2}{*}{ Monthly income } & Below 2000000 won & 166 & 2.9 & 0.118 & 95 & 4.1 & 0.009 & 71 & 2.1 & 0.003 \\
\hline & Above 2000000 won & 102 & 2.4 & & 97 & 2.8 & & 5 & 0.6 & \\
\hline \multirow[t]{2}{*}{ Smoking } & Yes & 149 & 3.3 & 0.001 & 147 & 3.4 & 0.317 & 2 & 0.9 & 0.436 \\
\hline & No & 119 & 2.2 & & 44 & 2.8 & & 74 & 1.9 & \\
\hline \multirow[t]{2}{*}{ Alcohol drinking } & Yes & 189 & 2.7 & 0.942 & 155 & 3.2 & 0.560 & 34 & 1.5 & 0.132 \\
\hline & No & 78 & 2.6 & & 36 & 3.6 & & 42 & 2.2 & \\
\hline \multirow[t]{2}{*}{ Hypertension } & Yes & 24 & 4.8 & 0.003 & 19 & 6.6 & 0.003 & 5 & 2.3 & 0.229 \\
\hline & No & 155 & 2.3 & & 117 & 3.1 & & 38 & 1.4 & \\
\hline \multirow[t]{2}{*}{ Obesity } & Yes & 8 & 3.4 & 0.391 & 6 & 4.2 & 0.474 & 2 & 2.1 & 0.390 \\
\hline & No & 170 & 2.5 & & 130 & 3.3 & & 41 & 1.4 & \\
\hline \multirow[t]{6}{*}{ Industries } & Agriculture & 45 & 6.2 & 0.000 & 22 & 6.2 & 0.000 & 23 & 6.2 & 0.000 \\
\hline & Mining & 3 & 37.5 & & 2 & 28.6 & & 1 & 100.0 & \\
\hline & Manufacturing & 59 & 3.5 & & 48 & 3.8 & & 11 & 2.6 & \\
\hline & Construction & 28 & 3.7 & & 28 & 4.1 & & 0 & 0.0 & \\
\hline & Transportation & 16 & 3.0 & & 16 & 3.4 & & 0 & 0.0 & \\
\hline & Others & 116 & 1.8 & & 76 & 2.5 & & 40 & 1.2 & \\
\hline \multirow[t]{3}{*}{ Occupations } & Manage/professional work & 17 & 1.8 & 0.000 & 13 & 2.2 & 0.000 & 4 & 1.2 & 0.000 \\
\hline & Manual work & 183 & 4.8 & & 136 & 5.3 & & 47 & 3.7 & \\
\hline & Office service work & 60 & 1.2 & & 37 & 1.5 & & 22 & 0.9 & \\
\hline \multirow{4}{*}{$\begin{array}{l}\text { Employment } \\
\text { status }\end{array}$} & Self-employed without employees & 73 & 4.2 & 0.000 & 51 & 4.2 & 0.005 & 23 & 4.3 & 0.000 \\
\hline & Self-employed with employees & 6 & 1.0 & & 5 & 1.0 & & 1 & 0.7 & \\
\hline & Employed & 179 & 2.5 & & 136 & 3.3 & & 42 & 1.4 & \\
\hline & Unpaid family workers & 10 & 1.9 & & 0 & 0.0 & & 10 & 2.1 & \\
\hline \multirow{4}{*}{$\begin{array}{l}\text { Number of } \\
\text { employees }\end{array}$} & $1-4$ & 126 & 2.9 & 0.030 & 78 & 3.5 & 0.169 & 48 & 2.4 & 0.084 \\
\hline & $5-49$ & 74 & 2.2 & & 55 & 2.7 & & 19 & 1.4 & \\
\hline & $50-299$ & 33 & 2.5 & & 28 & 3.2 & & 5 & 1.1 & \\
\hline & $\geq 300$ & 29 & 3.9 & & 26 & 4.6 & & 2 & 1.2 & \\
\hline \multirow{4}{*}{$\begin{array}{l}\text { Working period } \\
\quad \text { (years) }\end{array}$} & $<5$ & 92 & 1.8 & 0.000 & 64 & 2.5 & 0.000 & 28 & 1.1 & 0.000 \\
\hline & $\geq 5-<10$ & 41 & 2.3 & & 30 & 2.8 & & 12 & 1.8 & \\
\hline & $\geq 10-<20$ & 49 & 2.7 & & 42 & 3.4 & & 7 & 1.3 & \\
\hline & $\geq 20$ & 85 & 6.0 & & 55 & 5.7 & & 29 & 6.5 & \\
\hline \multirow[t]{2}{*}{ Noise } & Exposure & 92 & 6.5 & 0.000 & 78 & 7.2 & 0.009 & 13 & 3.8 & 0.010 \\
\hline & Non-exposure & 176 & 2.0 & & 113 & 2.4 & & 63 & 1.6 & \\
\hline \multirow[t]{2}{*}{ Vibration } & Exposure & 101 & 6.4 & 0.000 & 89 & 7.0 & 0.000 & 12 & 3.9 & 0.012 \\
\hline & Non-exposure & 166 & 2.0 & & 103 & 2.2 & & 64 & 1.7 & \\
\hline \multirow[t]{2}{*}{ Chemiclas } & Exposure & 80 & 6.7 & 0.000 & 73 & 7.7 & 0.000 & 7 & 2.8 & 0.217 \\
\hline & Non-exposure & 187 & 2.1 & & 119 & 2.4 & & 69 & 1.8 & \\
\hline
\end{tabular}

*the number of subjects who experienced hearing loss 
compared to that of office service work. In relation to the employment status, ORs were 4.92 (95\% CI, 2.06-11.75) for the self-employed without employees, where general employees had 2.89 (95\% CI, 1.23-6.77). ORs were 1.54 (95\% CI,
1.08-2.18) for people who worked for over 10 to 20 years and 3.45 (95\% CI, 2.55-4.66) for people who worked over 20 years, compared to that of people who worked less than 5 years. ORs were 3.29 (95\% CI, 2.54-4.27) for people exposed

Table 3. Univariate and multivariate logistic regression analyses of factors affecting hearing loss

\begin{tabular}{|c|c|c|c|c|}
\hline \multirow{2}{*}{ Variables } & \multicolumn{2}{|c|}{ Univariate } & \multicolumn{2}{|c|}{ Multivariate } \\
\hline & OR & $95 \% \mathrm{Cl}$ & OR & $95 \% \mathrm{Cl}$ \\
\hline Sex (male/female) & $1.83^{*}$ & $1.40-2.39$ & $1.74^{*}$ & $1.03-2.96$ \\
\hline \multicolumn{5}{|l|}{ Age } \\
\hline$<30$ & Reference & & Reference & \\
\hline$\geq 30-<40$ & 1.25 & $0.70-2.25$ & 1.06 & $0.55-2.05$ \\
\hline$\geq 40-<50$ & $2.72^{*}$ & $1.61-4.59$ & $2.11^{*}$ & $1.14-3.89$ \\
\hline$\geq 50$ & $4.02 *$ & $2.42-6.66$ & $2.24^{*}$ & $1.19-4.20$ \\
\hline Region (others/major city) & $1.37^{*}$ & $1.07-1.76$ & 1.17 & $0.85-1.61$ \\
\hline Education (high school/college) & $2.12^{*}$ & $1.59-2.82$ & 0.99 & $0.64-1.55$ \\
\hline Monthly income (below 2000000/above 2000000 won) & 1.23 & $0.96-1.58$ & 1.23 & $0.81-1.87$ \\
\hline Smoking (yes/no) & $1.54^{*}$ & $1.21-1.97$ & 1.09 & $0.71-1.67$ \\
\hline Alcohol drinking (yes/no) & 1.01 & $0.77-1.32$ & 1.02 & $0.69-1.52$ \\
\hline Hypertension (yes/no) & $2.05^{*}$ & $1.32-3.19$ & 1.29 & $0.79-2.11$ \\
\hline Obesity (yes/no) & 1.43 & $0.70-2.90$ & 1.58 & $0.75-3.34$ \\
\hline \multicolumn{5}{|l|}{ Industries } \\
\hline Others & Reference & & Reference & \\
\hline Transportation & 1.64 & $0.96-2.80$ & 0.63 & $0.30-1.30$ \\
\hline Construction & $2.11^{*}$ & $1.39-3.21$ & 0.62 & $0.36-1.10$ \\
\hline Manufacturing & $1.95^{*}$ & $1.42-2.68$ & 0.75 & $0.48-1.15$ \\
\hline Agriculture & $3.55^{*}$ & $2.50-5.06$ & 0.00 & \\
\hline Mining & $35.33^{*}$ & $8.44-147.85$ & 6.70 & $0.99-45.20$ \\
\hline \multicolumn{5}{|l|}{ Occupations } \\
\hline Office service work & Reference & & Reference & \\
\hline Manage/professional work & 1.49 & $0.86-2.57$ & $2.21^{*}$ & $1.18-4.15$ \\
\hline Manual work & $4.02 *$ & $2.99-5.41$ & $2.73^{*}$ & $1.69-4.41$ \\
\hline \multicolumn{5}{|l|}{ Employment status } \\
\hline Self-employed with employees & Reference & & Reference & \\
\hline Self-employed without employees & $4.92 *$ & $2.06-11.75$ & $2.72 *$ & $1.09-6.78$ \\
\hline Employed & $2.89^{*}$ & $1.23-6.77$ & $2.67^{*}$ & $1.11-6.40$ \\
\hline Unpaid family workers & 2.08 & $0.73-5.94$ & 1.23 & $0.40-3.83$ \\
\hline \multicolumn{5}{|l|}{ Number of employees } \\
\hline $1-4$ & Reference & & Reference & \\
\hline $5-49$ & $0.74^{*}$ & $0.55-0.99$ & 0.69 & $0.45-1.04$ \\
\hline $50-299$ & 0.83 & $0.56-1.23$ & 0.86 & $0.51-1.45$ \\
\hline$\geq 300$ & 1.33 & $0.88-2.02$ & 1.15 & $0.64-2.08$ \\
\hline \multicolumn{5}{|l|}{ Working period (years) } \\
\hline$<5$ & Reference & & Reference & \\
\hline$\geq 5-<10$ & 1.30 & $0.90-1.89$ & 1.43 & $0.93-2.21$ \\
\hline$\geq 10-<20$ & $1.54^{*}$ & $1.08-2.18$ & 1.28 & $0.79-2.08$ \\
\hline$\geq 20$ & $3.45^{*}$ & $2.55-4.66$ & $2.07^{*}$ & $1.36-3.15$ \\
\hline Noise (exposure/non-exposure) & $3.29 *$ & $2.54-4.27$ & $1.72 *$ & $1.14-2.58$ \\
\hline Vibration (exposure/non-exposure) & $3.40^{*}$ & $2.64-4.38$ & $1.53^{*}$ & $1.02-2.30$ \\
\hline Chemicals (exposure/non-exposure) & $3.29 *$ & $2.51-4.30$ & $1.58^{*}$ & $1.11-2.24$ \\
\hline
\end{tabular}

* $p<0.05$. OR: odds ratio, Cl: confidence interval 
to noise, 3.40 (95\% CI, 2.64-4.38) for people exposed to vibration, and 3.29 (95\% CI, 2.51-4.30) for people exposed to chemicals when referencing whether subjects were exposed to noise, vibration, and chemicals or not. In the case of the multivariate logistic regression analysis, statistically significant adjusted ORs were shown as follow: 1.74 (95\% CI, 1.03-2.96) for males, 2.11 (95\% CI, 1.14-3.89) for those in their 40s, $2.24(95 \% \mathrm{CI}, 1.19-4.20)$ for those in their 50s, $2.21(95 \%$ CI, 1.18-4.15) for manage/professional work, 2.73 (95\% CI, 1.69-4.41) for manufacturing, 2.07 (95\% CI, 1.36-3.15) for those who work for more than 20 years, 1.72 (95\% CI, 1.142.58) for noise exposure, 1.53 (95\% CI, 1.02-2.30) for vibration exposure and $1.58(95 \% \mathrm{CI}, 1.11-2.24)$ for chemical exposure (Table 3 ).

\section{Exposure to hazardous factors that affect hearing loss in survey subjects survey subjects}

In the univariate logistic regression analysis according to amount of noise exposure, ORs gradually increased with the statistical significance as follows: 86 people $(1.6 \%)$ for absolutely no exposure, 62 people $(2.7 \%$; OR, 1.66 ; 95\% CI, $1.19-2.31)$ for almost no exposure, 28 people $(2.9 \%$; OR, $1.85 ; 95 \%$ CI, 1.20-2.84) with exposure of $1 / 4$ of working hours, 29 people $(5.3 \%$; OR, 3.36; 95\% CI, 2.18-5.18) with exposure of half of working hours, 22 people $(6.1 \%$; OR, 3.92; $95 \%$ CI, 2.41-6.36) with exposure of $3 / 4$ of working hours, 28 people $(7.8 \%$; OR, 5.18; 95\% CI, 3.33-8.05) with exposure of almost all of working hours, and 13 people (8.1\%; OR, 5.45; 95\% CI, 2.99-9.95) exposed throughout all working hours. Also, in the multivariate analyses that controlled sex, age, working period, smoking, alcohol drinking, hypertension, and obesity, the adjusted ORs were gradually increased with the statistical significance in accordance with the amount of noise exposure as follows: 2.02 (95\% CI, 1.30-3.13), 2.47 (95\% CI, 1.45-4.22), 4.03 (95\% CI, 2.38-6.81), 4.49 (95\% CI, 2.51-8.05), 5.36 (95\% CI, 3.18-9.03), and $6.41(95 \%$ CI, 3.22-12.75)(Table 4).

Univariate logistic regression analysis according to exposure of hazardous factors (existence of exposure, sole exposure, or combined exposures) revealed that ORs gradually increased with statistical significance as the hazardous factors increased as follows: 139 people (1.8\%) for non-exposure, 12 people $(4.3 \%$; OR, 2.34; 95\% CI, 1.27-4.31) for noise-only exposure, 14 people $(3.7 \%$; OR, 2.02; 95\% CI, 1.15-3.56) for vibration-only exposure, 21 people $(5.0 \%$; OR, 2.84; $95 \%$ CI, 1.78-4.54) for chemicals-only exposure, 20 people (4.5\%; OR, 2.52; 95\% CI, 1.56-4.07) for noise and vibration exposures, 39 people $(6.1 \%$; OR, 3.52; 95\% CI, 2.45-5.07) for noise and chemicals exposures, and 20 people $(9.1 \%$; OR, 5.41; 95\% CI, 3.32-8.82) for combined exposure of noise, vibration and chemicals. In the multivariate analyses that controlled sex, age, working period, smoking, alcohol drinking, hypertension, and obesity, each OR increased with the statistical significance as the number of hazardous factors in-

Table 4. Logistic regression analyses of amount of noise exposure affecting hearing loss

\begin{tabular}{|c|c|c|c|c|c|}
\hline \multirow{2}{*}{ Amount of noise exposure } & \multirow{2}{*}{ No. of cases (\%) } & \multicolumn{2}{|c|}{ Univariate } & \multicolumn{2}{|c|}{ Multivariate* } \\
\hline & & OR & $95 \% \mathrm{Cl}$ & OR & $95 \% \mathrm{Cl}$ \\
\hline Absolutely no exposure & $86(1.6)$ & Reference & & Reference & \\
\hline Almost no exposure & $62(2.7)$ & 1.66 & $1.19-2.31$ & 2.02 & $1.30-3.13$ \\
\hline Exposure of $1 / 4$ of working hours & $28(2.9)$ & 1.85 & $1.20-2.84$ & 2.47 & $1.45-4.22$ \\
\hline Exposure of half of working hours & $29(5.3)$ & 3.36 & $2.18-5.18$ & 4.03 & $2.38-6.81$ \\
\hline Exposure of $3 / 4$ of working hours & $22(6.1)$ & 3.92 & $2.41-6.36$ & 4.49 & $2.51-8.05$ \\
\hline Exposure of almost all of working hours & $28(7.8)$ & 5.18 & $3.33-8.05$ & 5.36 & $3.18-9.03$ \\
\hline Exposure throughout all working hours & $13(8.1)$ & 5.45 & $2.99-9.95$ & 6.41 & $3.22-12.75$ \\
\hline
\end{tabular}

*adjusted for sex, age, work duration, smoking, alcohol drinking, hypertension, obsity. OR: odds ratio, Cl: confidence interval

Table 5. Logistic regression analyses of hazardous exposure affecting hearing loss

\begin{tabular}{|c|c|c|c|c|c|}
\hline \multirow{2}{*}{ Exposure factors } & \multirow{2}{*}{ No. of cases (\%) } & \multicolumn{2}{|c|}{ Univariate } & \multicolumn{2}{|c|}{ Multivariate* } \\
\hline & & OR & $95 \% \mathrm{Cl}$ & OR & $95 \% \mathrm{Cl}$ \\
\hline Non-exposure & $139(1.8)$ & Reference & & Reference & \\
\hline Noise-only exposure & $12(4.3)$ & 2.34 & $1.27-4.31$ & 3.46 & $1.76-6.80$ \\
\hline Vibration-only exposure & $14(3.7)$ & 2.02 & $1.15-3.56$ & 2.22 & $1.08-4.56$ \\
\hline Chemicals-only exposure & $21(5.0)$ & 2.84 & $1.78-4.54$ & 2.91 & $1.66-5.11$ \\
\hline Noise and vibration exposure & $20(4.5)$ & 2.52 & $1.56-4.07$ & 3.10 & $1.83-5.26$ \\
\hline Noise and chemicals exposure & $39(6.1)$ & 3.52 & $2.45-5.07$ & 3.25 & $2.08-5.06$ \\
\hline Noise, vibration and chemicals exposure & $20(9.1)$ & 5.41 & $3.32-8.82$ & 5.80 & $3.36-10.00$ \\
\hline
\end{tabular}

*adjusted for sex, age, work duration, smoking, alcohol drinking, hypertension, obsity. OR: odds ratio, Cl: confidence interval 
creased as follows: 3.46 (95\% CI, 1.76-6.80) for noise-only exposure, 2.22 (95\% CI, 1.08-4.56) for vibration-only exposure, 2.91 (95\% CI, 1.66-5.11) for chemicals-only exposure, 3.10 (95\% CI, 1.83-5.26) for noise and vibration exposures, 3.25 (95\% CI, 2.08-5.06) for noise and chemicals exposures, and $5.80(95 \% \mathrm{CI}, 3.36-10.00)$ for combined exposure of noise, vibration and chemicals (Table 5).

\section{Discussion}

This research discovered that there were correlations with the occurrence of hearing loss that is generated by sociodemographic variables such as sex, age and education level, individual risks such as smoking, and hypertension, and occupational risks such as type of industry, occupations, employment status, and working period. It further found additional risks of hearing loss, such as isolated exposure to noise, vibration, and chemicals, and the combined exposures to these hazards after the corrections of individual risk factors like sex, age, smoking/alcohol drinking, hypertension, and obesity. Also, the study of hearing loss, using the data from the National Health and Nutrition Examination Survey 1999-2004, presented that noise exposure, hypertension, diabetes, and smoking (over 20 pack of cigarette per year) could influence the prevalence rate of hearing loss besides sex and age factors. ${ }^{7)}$

In this research, the prevalence rate of hearing loss was $2.7 \%$, which was lower than that of other studies, and even lower than when the standards to define a hearing impairment was the pure-tone average (PTA) of hearing test. Kim, et al. ${ }^{8)}$ examined 5724 subjects from Seoul, Gyeonggi, and Gangwon provinces, and proved the incidence rate of heaing loss was $9.4 \%$ and $1.4 \%$ for $27 \mathrm{~dB}$ HL or higher and $41 \mathrm{~dB}$ HL or higher criterion, respectively. Agrawal, et al. ${ }^{7)}$ indicated that $16.1 \%$ of US adults (29 million Americans, $7.3 \%$ bilateral and $8.9 \%$ unilateral) had speech-frequencies hearing loss (PTA of $25 \mathrm{~dB}$ or higher at $0.5,1,2$, and $4 \mathrm{kHz}$ ), and 30\% (55 million Americans, 12\% unilateral and 19\% bilateral) had high-frequencies hearing loss (pure-tone mean of $25 \mathrm{~dB}$ or higher at 3, 4, and $6 \mathrm{kHz}$ ).

Based on sex, the hearing threshold and the ratio of hearing loss for males were generally higher than those of females. Although OR for males was 1.74 fold higher in this research, Kim, et al. ${ }^{8)}$ study, in 2000, indicated that the ratio for males was three-fold higher than that of females at the ratio of hearing loss of the $41 \mathrm{~dB}$ HL PTA criterion. In Agrawal, et al. ${ }^{7)}$ research, in 2008, OR was $2.4(1.7-3.5)$ and high-frequency hearing loss was $5.5(4.0-7.5)$, which focused on the standards of bilateral hearing loss. In the study on hearing for older people, the hearing threshold for males was higher than that of females at over the $1 \mathrm{kHz}$ frequency, and vise versa below the $1 \mathrm{kHz}$ frequency. This result could be explained as being caused by environmental factors, like noise exposure of males, and physiological factors, like high vascular diseases of females. ${ }^{9)}$

Even though age is not a direct factor that affects hearing loss, it can have significant indirect impact on hearing because the effects of presbycusis increase as people get older. There was a correlation between age and hearing loss, and the prevalence rate of hearing loss significantly increased with age. ${ }^{7)}$ With an increase of age, the hearing threshold can be raised and the hearing loss at the high frequency is higher than that of the low frequency. If any factor among the forms of noise exposure and the increase of age acts on people, they are enough to cause pathological, physiological, or histopathological disorders. More specifically, based on animal tests, an increase in age and noise exposure has an effect in increasing the sensitivity of NIHL.

Although there is controversy on whether the relation between age and noise exposures is additive or correlated, the major opinion is that it is restrictive and additive. The study in 1999 by Lee, et al. ${ }^{10)}$ represented that the increase in age and level of noise exposure, that affects changes in hearing, had an impact on the hearing threshold independently and there were additive effects. As a result of the analysis of age, noise exposure, blood pressure and serum cholesterol in the 2001 study of Toppila, et al., ${ }^{11)}$ the elderly subjects were more susceptible to NIHL than younger subjects. Also, factors independently but causally related to age were important in the development of NIHL among workers exposed to noise levels below $98 \mathrm{~dB}(\mathrm{~A})$.

Advanced permanent threshold shift apart from noise exposure in population surveys has been explained to arise from biological and environmental factors. Nevertheless, the data on NIHL in carefully controlled studies show considerable case-to-case variation, indicating that individual susceptibility also plays a significant role. Factors such as elevated blood pressure, altered lipid metabolism, smoking, and genetic factors are believed to aggregate in NIHL. More specifically, the effects of noise were partially concealed and the significance of noise exposure may have been rejected by the confounding factors in the occurrence of hearing loss. However, a review of controlled research shows that the influence of these intrinsic variables is relatively small and cannot explain the wide range of hearing loss observed in demographic studies. ${ }^{12)}$

In regards to the effects of smoking on the auditory system, it can be possible to depict the direct ototoxic effects on the outer hair cells of the inner ear. Smoking increases the carboxyhemoglobin in the blood resulting in a decrease in the amount oxygen that can be used by cells. Nicotine also contributes to 
hearing impairment. Its action is relate to blood vessel artherosclerosis. The cochlear artery especially its end artery in the inner part of higher frequency cochlear will be affected by this artherosclerotic change. Smoking, in relation to age, has multiplicative adverse effect on hearing impairment. The prevalence rate of hearing impairment increased with the increasing number of pack-years. A marked increase in hearing impairment prevalence occurred for the subjects who smoked more than 20 pack-years. The increase of hearing threshold by frequency was greater at the higher frequency. As risk factors for the disability of hearing loss, age and the amount of smoking was indicated to independently affect hearing impairment. Smoking affects hearing more harshly when combined with noise. Anti-smoking education is necessary, since smoking can accelerate hearing loss, with this influence increasing through the interactions with noise. ${ }^{13)}$

The effect of alcohol drinking on the hearing is not very clear. An association with chronic alcohol abuse has been observed, but with moderate alcohol intake, the results are less clear. In a study of Upile, et al., ${ }^{14)}$ the hearing thresholds of women were more affected than men. Slim and healthy people were least affected, whilst older subjects or those with a previous history of heavy drinking were most affected. There was a positive association between increasing breath alcohol concentration and the magnitude of the increase in hearing threshold for most hearing frequencies. The effect of alcohol on hearing was also found to be reversible in the short term but long-term permanent threshold changes cannot be excluded. In contrast, current smokers showed a significantly increased risk of hearing loss compared with non-smokers, while heavy drinkers did not show an increased risk compared to non-drinkers. In addition, there was a decrease of the risk of hearing loss in case of light drinking, which caused a U-shaped response of hearing loss among the amount of drinking. ${ }^{15)}$ A European population-based multicenter study also depicted that moderate alcohol consumption was inversely correlated with hearing loss. ${ }^{16)}$

It has been argued that smoking or overweight might contribute to hearing disorder by atherogenic narrowing of the nutrient arteries to the cochlea. Carotid intima-media thickness (CIMT) is a surrogate marker for generalized atherosclerosis. In a study that examined the relationship between CIMT and hearing disorder, CIMT remained a predictor of hearing disorder (OR 1.8, 95\% CI 1.0-3.2) after adjustment for cigarettes per day, waist circumference, diabetes, exposure to noise, age and sex. Cigarettes per day and waist circumference were related to CIMT but not to hearing disorder. ${ }^{17)}$ Although the effect of the body mass index (BMI) decreased when cardiovascular diseases and smoking were controlled as confounding fac- tors, it was shown that high BMI was related with high hearing threshold. ${ }^{16)}$

Hearing loss by industrial chemical exposures in the workplace, was various, complicated, and controversial. Recent research is uncovering the audiologic effects on humans exposed to chemicals, accompanied through experiments on animals. Industrial ototoxic materials that cause hearing loss were as follows: heavy metals such as arsenic, cobalt, lead, lithium, cadmium and manganese, and chemicals such as carbon monoxide, carbon disulfide, trichloroethylene, xylene, toluene, styrene, n-hexane, dimethylsulfoxide and carbon tetrachloride. ${ }^{18)}$ Ototoxic chemicals can have reversible or irreversible effects that impair the sense of hearing and balance. They can affect the structure and/or the function of the inner ear (auditory and vestibular apparatus) and the neural pathways from the inner ear to the auditory cortex in the brain. ${ }^{19)}$ If certain predisposing conditions are present, the risk of ototoxicity is increased. These conditions include impaired renal functioning, pregnancy, inherited susceptibility to ototoxicity, and the effects of noise. ${ }^{20)}$

In a 2011 research by Sliwinska-Kowalska, et al. ${ }^{21)}$ a 2-4 $\mathrm{kHz}$ threshold of organic solvent+noise combined exposure group was significantly higher than that of the solvent-only exposure group, and a $1-8 \mathrm{kHz}$ hearing threshold of the organic solvent exposure group was significantly and highly indicated, compared to the control group. The relative risk (RR) of hearing loss in the solvent-only exposure group was significantly increased [RR 4.4 and 2.8 for noise exposure of $<80$ $\mathrm{dB}(\mathrm{A})$ and $<85 \mathrm{~dB}(\mathrm{~A})$, respectively] in a wide range of frequencies $(2-8 \mathrm{kHz})$. In their other study in 2005 , OR of hearing loss related with the particular exposure to chemicals was 2.4 (95\% CI 1.59-3.74) in case of solvent mixture, $3.9(95 \%$ CI 2.4-6.2) in case of styrene and 5.3 (95\% CI 2.6-10.9) in case of n-hexane and toluene exposure. The odds of developing hearing loss substantially increased in the case of combined exposure to organic solvents and noise as compared to isolated exposure to each of these hazards. The highest OR (over 20-fold) was demonstrated in subgroups of subjects exposed simultaneously to noise and two ototoxic solvents. ${ }^{22)}$ In general, the simultaneous exposure to organic solvents and noise seems to enhance the hearing deficit if compared with isolated exposures.

Thus, the combined effect of organic solvents and noise should be carefully reviewed even for the noise level below exposure limit, which suggests that preventive program for hearing loss is facing transition point. Also, workers who are exposed to major ototoxic chemicals need to undergo hearing screenings. The American Conference of Governmental Industrial Hygienists (ACGIH) is considering whether current ex- 
posure limits are adequate to minimize the possibility of potentiating NIHL via combined exposures. ACGIH recommends audiometric monitoring for exposures to noise in combination with toluene, lead, manganese, and lists other substances under current investigation for ototoxicity.

Commonly, it is known that the vibration hand tools generate cause vibration-induced disease. However, in many epidemiological studies, the vibrations derived by hand tools causes NIHL and vibration-induced disease, and can show significantly higher NIHL for worker groups experiencing vibration-induced disease. Thus, long-term vibration exposure contributes to the generation of NIHL, or can cause a synergistic effect. Although it is not clear what impact vibration has on hearing, the effect on peripheral blood vessels can be assumed to influence the deterioration of NIHL. Concurrent exposure to noise and vibration can cause vasoconstriction in the cochlea by affecting the sympathetic nervous system, which can contribute to temporary hearing loss by the decreased blood flow.

According to Kaimio, et al., ${ }^{23)}$ whole-body vibration and noise increased average hearing threshold as much as $5 \mathrm{~dB}$. In the Chinchilla research, while there were no effects on the temporary hearing loss through vibration, the combined exposure of noise and vibration could generate a $10 \mathrm{~dB}$ temporary hearing loss. ${ }^{24)}$ In the conducted experiment with workers exposed to noise $[90 \mathrm{~dB}(\mathrm{~A})]$ and vibration $\left(30 \mathrm{~m} / \mathrm{s}^{2}, 60 \mathrm{~Hz}\right)$, exposure to vibration alone caused almost no hearing threshold changes at every frequency tested. But exposure to noise or a combination of vibration and noise caused a significant increase in temporary threshold shifts (TTSs) at 4 and $6 \mathrm{kHz}$. Moreover, exposure to a combination of vibration and noise caused significantly higher TTSs than exposure to noise at 4 and $6 \mathrm{kHz}^{25)}$ Pintér ${ }^{26)}$ indicated that the prevalence rate of sensorineural hearing loss, due to the noise exposure was unexpectedly higher among the tractor drivers, which was assumed to be caused by the whole-body vibration from the tractor. In the noise susceptibility research on hearing for male workers in forestry, the hearing loss of subjects having vibration-induced white fingers (VWF) was faster than that of the subjects without VWF. In this respect, the hearing of subjects were vulnerable to noise, and it is possible that additional vulnerabilities related to noise exposure can be caused since an increase in the activity of the sympathetic nervous system generates changes such as vasoconstriction. ${ }^{27)}$

In this research, it was able to identify the prevalence rate of hearing loss, including workers in self-employed, unpaid family workers, and employees industries like agriculture, forestry, fishing, wholesale, and retail businesses, from the second KWCS. Also, the effects of all occupational/non-occupa- tional risk factors of hearing loss could be examined. In particular, in the case of occupational factors, it was able to investigate the effects by the sole exposure of vibration and chemicals other than noise, and the additional risks of hearing loss by combined exposures. Furthermore, it was discovered that these occupational factors could be affected by industry type, occupations, and employment status besides physical/ chemical hazards. Therefore, it should be considered as an institutional policy of hearing management for works, aside from the management of NIHL by noise exposure.

However, there were limitations in examining the effects of the occupational factors in regards to hearing loss precisely. The first limitation was that this research was defined, not as a hearing threshold, but as a hearing problem in the survey. Secondly, hearing loss was just examined according to the exposure time, and did not perform exact exposure evaluations in regards to major hazardous factors that cause hearing loss, such as noise, vibration, and chemicals. The factors that influence hearing loss occurrence were not excluded after identifying these factors, such as otologic disease, chronic disease, and especially, conductive hearing loss. Also, since this data was obtained through a self-report survey it was not an exact diagnosis of the occupational disease, and the occurrences of hearing loss and the prevalence for the past 12 months were unclear. As a result, there was a possibility of under- or over-estimation compared with the evaluation of hearing loss by the hearing threshold according to acute/chronic occurrences or progress of the hearing defect. Therefore, further quantitative studies are needed for a more exact assumption of the incidence rates of hearing loss and risk evaluations in regards to hearing and exposure risks.

\section{Conclusion}

The overall occupational and non-occupational risk factors related to employees' hearing loss were reviewed. In addition to the exposure to noise, occupational risks of hearing loss, such as isolated exposure to vibration and chemicals, and combined exposure to noise and these hazards, were identified. Multiple exposure to hazards, along with prolonged noise exposure increased the risk of hearing loss. In order to achieve accurate estimation of the incidence rate of hearing loss and its risk assessment, quantitative research on hearing and the risks of exposure is necessary.

\section{REFERENCES}

1) Fransen E, Lemkens N, Van Laer L, Van Camp G. Age-related hearing impairment (ARHI): environmental risk factors and genetic prospects. Exp Gerontol 2003;38:353-9. 
2) Lee WJ, Cha ES, Moon EK. Disease Prevalence and Mortality among Agricultural Workers in Korea. J Korean Med Sci 2010;25(Suppl): S112-8.

3) Occupational disease in Europe in 2001. [cited 2011 Apr 11]. Available from: URL: http://epp.eurostat.ec.europa.eu/portal/page/portal/product_details/publication?p_product_code=KS-NK-04-015.

4) European working conditions survey (EWCS). [cited 2011 Apr 26]. Available from: URL: http://www.eurofound.europa.eu/ewco/surveys/index.htm.

5) Park J, Lee N. First Korean Working Conditions Survey: a comparison between South Korea and EU countries. Ind Health 2009;47: 50-4.

6) Second Korean Working Conditions Survey (2010) in press. Occupational Safety \& Healthy Research Institute, Korea Occupational Safety \& Health Agency.

7) Agrawal Y, Platz EA, Niparko JK. Prevalence of hearing loss and differences by demographic characteristics among US adults: data from the National Health and Nutrition Examination Survey, 19992004. Arch Intern Med 2008;168:1522-30.

8) Kim HN, Kim SG, Lee HK, Ohrr H, Moon SK, Chi J, et al. Incidence of presbycusis of Korean populations in Seoul, Kyunggi and Kangwon provinces. J Korean Med Sci 2000;15:580-4.

9) Garstecki DC, Erler SF. Older women and hearing. Am J Audiol 1995;4:41-6.

10) Lee JH, Lee CR, Yoo CI, Yaang SR, Kim OH, Cho BM, et al. The effect of noise exposure and age on the changes of group mean hearing threshold level: annual follow-up studies for seven years. Korean J Occup Environ Med 1999;11:137-52.

11) Toppila E, Pyykkö I, Starck J. Age and noise-induced hearing loss. Scand Audiol 2001;30:236-44.

12) Henderson D, Subramaniam M, Boettcher FA. Individual susceptibility to noise-induced hearing loss: an old topic revisited. Ear Hear 1993;14:152-68.

13) Noorhassim I, Rampal KG. Multiplicative effect of smoking and age on hearing impairment. Am J Otolaryngol 1998;19:240-3.

14) Upile T, Sipaul F, Jerjes W, Singh S, Nouraei SA, El Maaytah M, et al. The acute effects of alcohol on auditory thresholds. BMC Ear Nose Throat Disord 2007;7:4.

15) Itoh $A$, Nakashima $T$, Arao $H$, Wakai $K$, Tamakoshi $A$, Kawamura $\mathrm{T}$, et al. Smoking and drinking habits as risk factors for hearing loss in the elderly: epidemiological study of subjects undergoing routine health checks in Aichi, Japan. Public Health 2001;115:192-6.

16) Fransen E, Topsakal V, Hendrickx JJ, Van Laer L, Huyghe JR, Van Eyken E, et al. Occupational noise, smoking, and a high body mass index are risk factors for age-related hearing impairment and moderate alcohol consumption is protective: a European population-based multicenter study. J Assoc Res Otolaryngol 2008;9:264-76; discussion 261-3.

17) John U, Baumeister SE, Kessler C, Völzke H. Associations of carotid intima-media thickness, tobacco smoking and overweight with hearing disorder in a general population sample. Atherosclerosis 2007;195:e144-9.

18) Rybak LP. Hearing: the effects of chemicals. Otolaryngol Head Neck Surg 1992;106:677-86.

19) Nies E. Ototoxic substances at the workplace: a brief update. Arh Hig Rada Toksikol 2012;63:147-52.

20) D'Alonzo BJ, Cantor AB. Ototoxicity: etiology and issues. J Fam Pract 1983;16:489-94.

21) Sliwinska-Kowalska M, Zamyslowska-Szmytke E, Szymczak W, Kotylo P, Fiszer M, Dudarewicz A, et al. Hearing loss among workers exposed to moderate concentrations of solvents. Scand J Work Environ Health 2001;27:335-42.

22) Sliwinska-Kowalska M, Zamyslowska-Szmytke E, Szymczak W, Kotylo P, Fiszer M, Wesolowski W, et al. Exacerbation of noise-induced hearing loss by co-exposure to workplace chemicals. Environ Toxicol Pharmacol 2005;19:547-53.

23) Kaimio M, Jauhiainen T, Kohonen A, Tarkkanen J. Whole body infrasonic vibration effects on the cochlea. Environ Res 1970;3:425-9.

24) Hamernik RP, Henderson D, Coling D, Salvi R. Influence of vibration on asymptotic threshold shift produced by impulse noise. Audiology 1981;20:259-69.

25) Zhu S, Sakakibara H, Yamada S. Combined effects of hand-arm vibration and noise on temporary threshold shifts of hearing in healthy subjects. Int Arch Occup Environ Health 1997;69:433-6.

26) Pintér I. Hearing loss of forest workers and of tractor operators (interaction of noise with vibration). In: Proceeding of the international congress on noise as a public health problem, Arlington, Virginia, 1973. The USA Environmental Protection Agency, Office of Noise Abatement and Control, Washington, 1973. p.315-27.

27) Iki M, Kurumatani N, Moriyama T, Ogata A. Vibration-induced white finger and auditory susceptibility to noise exposure. Kurume Med J 1990;37Suppl:S33-44. 